\title{
Ecological Constraints for Intergenerational Transmission of Attachment
}

\author{
Abraham Sagi \\ University of Haifa, Israel \\ Marinus H. van IJzendoorn \\ Leiden University, The Netherlands \\ Miri Scharf, Tirtsa Joels, Nina Koren-Karie, \\ and Ofra Mayseless \\ University of Haifa, Israel

\section{Ora Aviezer} \\ School of Education of the Kibbutz Movement, Oranim, Israel \\ To determine whether the transmission of attachment across generations is \\ free from contextual constraints, adult attachment representations were \\ assessed in two kibbutz settings, home-based and communal sleeping. It was \\ hypothesised that under extreme child-rearing circumstances, such as the \\ communal sleeping arrangement, the transmission of attachment is not \\ evident, whereas in the more regular home-based environment the expected \\ transmission of attachment will be found. The participants were 45 mothers \\ and 45 infants, about equal numbers of boys and girls, from 20 kibbutz infant \\ houses with communal sleeping arrangements, and from 25 kibbutz infant \\ houses with home-based sleeping arrangements. Mothers were administered \\ the Adult Attachment Interview (AAI), and infants were assessed through the \\ Ainsworth Strange Situation. Among the home-based pairs, a correspondence \\ of $76 \%$ was found between AAI and Strange Situation classifications, whereas \\ the correspondence was only $40 \%$ in the communal sleeping group. It is argued
}

Requests for reprints should be sent to Abraham Sagi, Department of Psychology,University of Haifa, Haifa 31950, Israel; e-mail: SAGI@PSY.HAIFA.AC.IL.

The study was carried out with research grants awarded to the first author by the Israeli Academy of Science (grants no. 654/89 and 336/93) and to the second author by a PIONEER grant from the Netherlands Foundation for Scientific Research (NWO, grant no. PGS 59-256). Thanks are due to Chava Becker, Frank Donnell, Nili Dror, Yael Harel, and Moshe Tuvia for assistance in data collection. We are grateful for the co-operation and support provided by Arza Avrahami, Director of the Institute for Research on Kibbutz Education. The co-operation of all kibbutz members and children involved in the study is deeply appreciated. 
that living in a communal sleeping arrangement reduces the expected transmission of attachment.

Intergenerational transmission of attachment refers to the process through which parents' mental representation of their past attachment experiences influences their parenting behaviour and the quality of the attachment relationship with their children (Bowlby, 1973; Main, Kaplan, \& Cassidy, 1985). In recent years, the study of intergenerational transmission of attachment has drawn the attention of a growing number of researchers, mainly because an instrument became available to measure adult attachment representations (Adult Attachment Interview: George, Kaplan, \& Main, 1985; Main et al., 1985). In 18 studies of 854 families, a combined correlation of about .50 was found between the security of the parents' mental representation of attachment and the security of the child-parent attachment relationship. The correlation is comparable to a concordance rate of about $75 \%$ (Van IJzendoorn, 1995). Of course, an effect size of this magnitude provides strong support for the transmission hypothesis. At the same time, the impressive correlation between parental and children's attachment security does leave room for lack of transmission of attachment across generations. In some cases, secure parents might raise insecure children, and in other cases insecure parents might raise secure children.

In the past, the lack of transmission of attachment has mainly been attributed to errors of measurement. Because neither adult attachment security nor the children's attachment security can be measured with complete reliability, the correspondence between both measures is always lower than 100\% (Van IJzendoorn, 1992). Measurement error, however, might not be a sufficient explanation of nontransmissions. The transmission hypothesis takes into consideration lawful discontinuities, such that parents who have been raised under adverse circumstances work through their anxious attachment experiences and reach a balanced and a secure view of their past and present attachment relationships (Main et al., 1985). However, the transmission hypothesis at the same time is based on the idea that if the parent's state of mind with respect to attachment (as measured by the AAI) is secure/autonomous, their infant would be classified as securely attached in the Strange Situation.

The occurrence of nontransmissions should alert us to the alternative possibility that ecological factors might mediate the transmission of attachment across generations. We suggest that nontransmission not only derives from errors of measurements but that it also is based on interfering ecological factors. Our hypothesis is that under certain extreme circumstances the influence of the parental representation of attachment might be overridden by the ecological context in which children are being raised, and the expected transmission of attachment might not take place. 
The Israeli kibbutzim provide a child-rearing context for a test of the universality claim in attachment theory (Aviezer, Van IJzendoorn, Sagi, \& Schuengel, 1994). In particular, the kibbutzim adhering to the traditional practice of communal sleeping generate quite extreme life conditions for parents and their children. Does the transmission hypothesis hold even under such circumstances? The most unique characteristics of communal sleeping is that during the night, two watchwomen are responsible for all the children in the kibbutz under the age of 12 . These watchwomen are regular members of the kibbutz, and about every six months each spends a week monitoring a number of children's houses through intercoms from a central location, usually the infants' house. Thus, the implication of this arrangement is that during the night the adults (a total of about 50 different women) are often unfamiliar to the infants and unable to respond promptly to the infants' needs. Adults available at night do not have a durable bond with the infants.

Although kibbutz infants are exposed to multiple caregiving very early in their lives (Lavi, 1990), their care in the first year is shared by their mothers and caregivers in a unique arrangement. Following birth, kibbutz infants receive exclusive maternal care in the family's residence for a period of about three months. When their mothers return to work part time, the infants are brought to the infant house, where initially they are cared for jointly by the mother and the caregiver. Mothers are almost exclusively in charge of feeding, and they arrange their work schedule accordingly; caregivers are responsible for infants in the time between maternal visits. As mothers gradually increase their work hours during the second part of infants' first year, caregivers assume more responsibility for infants' needs. But it is not until infants' second year that they come under the full-time care of caregivers. These practices are observed by home-based as well as by communal kibbutzim (Aviezer et al., 1994).

Thus, from the second year of life, kibbutz children in both kibbutz settings are cared for by "metaplot" for about 9 hours each day (6 days per week), and spend the afternoon hours of 4-8 p.m. at home with their parents. Kibbutz fathers make themselves available for their children during the afternoon hours, and consequently they tend to spend more time with their infants than their urban counterparts (Sagi, Koren, \& Weinberg, 1987), but the responsibility for infants' care rests primarily with mothers. At about 8 p.m., one group of infants, those residing in "home-based" kibbutzim, remain with their families for the night and in that respect their life routine is similar to that of infants being raised under day-care conditions. The communally sleeping infants, however, are returned to the infants' houses to be settled for the night by their parents in the infants' house, and the infants remain there under the care of the night watchwoman until morning. 
Despite these unusual sleeping conditions, we assumed that mothers remain the primary attachment figure for kibbutz infants for two major reasons. First, even though caregiving was divided between mothers, fathers, and caregivers, parental involvement has been characterised differently from caregivers' involvement by outside observers (Rabin \& Beit-Hallahmi, 1982) as well as in maternal self-perceptions (Feldman \& Yirmiya, 1986). Mothers were perceived as emotional and directed toward need gratification, whereas caregivers were perceived as instrumental and goal directed. Second, data on attachment of kibbutz infants to their mothers show: (1) under-representation of avoidant classifications (Sagi et al., 1985; Sagi, Van IJzendoorn, Aviezer, Donnell, \& Mayseless, 1994a); (2) no unclassifiable cases (Sagi et al., 1985, 1994a); and (3) independence from infant-caregiver classifications (Sagi et al., 1985). These data correspond to the first three criteria suggested by Van IJzendoorn, Sagi, and Lambermon (1992) to evaluate whether relationships are correctly identified as attachment relationships. However, contrary to their fifth criterion infantmother classification did not predict later socioemotional functioning (Oppenheim, Sagi, \& Lamb, 1988). The best predictions of later outcomes were derived when both parental relationships jointly with relationships with caregivers were viewed as a network for infant attachment relationships (Sagi et al., 1995; Van IJzendoorn et al., 1992). These results suggest that mothers are indeed primary attachment figures for kibbutz infants raised in communal sleeping, or home-based sleeping kibbutzim, but there may be differences in how infant-mother relationships influence infants' development, and express maternal internal models of parenting.

In the present study, we compared kibbutz families who lived in a home-based arrangement with those who lived in a communal sleeping arrangement through a quasi-experimental design. We measured differences in transmission of attachment across generations in the two contexts, while controlling for potentially intervening factors. Sleeping arrangements were established by each kibbutz rather than by individual families, and they were primarily related to ideological differences (Aviezer et al., 1994). In our recent study (Sagi et al., 1994a) we demonstrated that infants raised in kibbutzim with communal sleeping were less securely attached to their mothers than infants raised in home-based kibbutzim. In that study, the difference in attachment security between the two childrearing arrangements was explained on the basis of contextual factors. It was hypothesised that although the mothers in the two arrangements might show the same attitudes, intentions, and behaviours, the most important and overriding determinant of the communal children's attachment security would be their mothers' inaccessibility at night. Consequently, even when mothers themselves have secure attachment representations, their infants experience inconsistent responsiveness to their signals, and might, 
therefore, develop insecure attachments. The interpretation defines an ecological constraint for intergenerational transmission of attachment.

In the present study we directly tested the hypothesis that the transmission of attachment across generations would be mitigated by the ecological context of the communal sleeping system. However, this is not a test of lawful discontinuities in the development of attachment (e.g. Lamb, Thompson, Gardner, \& Charnov, 1985; Rutter, Quinton, \& Hill, 1990; Sroufe, 1988), because such discontinuities pertain to the individual's lifespan and not ecological constraints for the transmission of attachment across generations.

\section{METHOD}

\section{Participants}

The participants were 45 fullterm developmentally healthy infants and their mothers from intact families, $14-22$ months old $(M=18.36$; SD $=2.33)$, boys and girls, from 20 kibbutz infant houses with communal sleeping arrangements, and from 25 kibbutz infant houses with home-based sleeping arrangements. Forty-eight mothers were asked to participate, but three mothers refused to complete the Adult Attachment Interview (AAI), see later. The mean age of the mothers was $31.50(\mathrm{SD}=4.39)$, and about one-third were kibbutz-born in both the communal sleeping and homebased arrangements.

The two groups were compared on the following variables to ascertain that any group difference in concordance was due to sleeping arrangements and not due to demographic differences in mothers and infants, or due to intervening variables. A background questionnaire provided biographical characteristics of the mother, including her age, number of children, education, professional training, and prior kibbutz experiences as a child. Data concerning potentially intervening variables consisted of the mothers' current job satisfaction, a self-appraisal of her separation anxiety from her infant, a direct observation of mother-infant interaction during a play session, and her attitudes towards the infants' house. Infants' background information and possible intervening variables included infants' ages, sex, perceived temperament, and critical early life events such as illness and separation from parents. Another critical comparison concerned the quality of care which was observed in each infants' house so as to examine the essential similarities in the daytime ecology of both groups of infants. With few exceptions, no differences between the communal-sleeping and homesleeping groups were found. A full description of these analyses is presented elsewhere (Sagi et al., 1994a). 


\section{Measures}

The Strange Situation Procedure. Infant-caregiver attachment is usually observed in the Strange Situation procedure (Ainsworth, Blehar, Waters, \& Wall, 1978) in which infant-caregiver interaction during a series of increasingly stressful episodes indicates the quality of their attachment relationship. Infant behaviour during reunion with the caregiver after two 3-minute separations is classified into four main categories of attachment. The securely attached group (B) shows minimal resistant and avoidant behaviour; these infants are somewhat upset when their caregiver leaves but her return has a calming effect on them. Avoidant infants (A) do not seek proximity or contact with their returning caregiver. Resistant or ambivalent infants $(C)$ seek contact with their returning caregiver, but at the same time resist the caregiver, and some are unable to achieve calmness during the 3-minute reunion episodes. Recently, Main and Solomon (1990) have suggested that these latter infants can be classified into a fourth group, namely, disorganised/disoriented (D). However, because the D-category has not been validated as thoroughly as the other classifications, especially in relation to its precursors and sequelae, we have used, for statistical purposes, the traditional ABC system.

Adult Attachment Interview (AAI). George et al. (1985) developed the AAI for assessing an adult's state of mind with respect to their own childhood attachment histories. The AAI is a semistructured interview (George et al., 1985) consisting of a series of 15 major questions as well as relevant probes for obtaining additional information regarding these questions. The questions focus on global descriptions of past experiences as well as on specific biographical events. The interviews are transcribed verbatim and rated on scales for inferred experiences: love, neglect, rejection, role reversal, and push to achieve; and scales for representations: idealisation, insistence on lack of memory, anger, lack of resolution of mourning, lack of resolution of trauma, coherency of text and of mind, passivity of thoughts, derogation of attachment relationships, and metacognitive monitoring regarding early and present experiences.

Analogous to the classification of the Strange Situation, the rating scales contribute to overall classification into three main AAI categories: (1) Dismissing of attachment (Ds), here the person avoids consideration of past relationships with attachment figures and has difficulty in discussing prior attachment experiences; (2) Preoccupied (E), here the person demonstrates an ambivalent consideration of past experiences, being preoccupied with past experiences, and still exhibiting anger toward attachment figures and about prior experiences; (3) Autonomous (F), the person is openly free to explore past experiences, and this accessibility to prior experiences is rather 
smooth whether they are positive or negative. A fourth category, Unresolved mourning or trauma (U), is conceptually most related to the D-type infant (Main \& Goldwyn, 1994). However, the inclusion of the Uand D-categories here is beyond the scope of this paper (Sagi et al., 1994b) and only the Ds, F, and E groups for the AAI, and the ABC Strange Situation categories were analysed in the present study.

Transcripts were rated by four judges, each trained by Mary Main and Erik Hesse. Inter-judge reliabilities ranged from $91 \%$ to $100 \%$ with kappas ranging from .82 to 1.00 . The AAI has been shown to have retrodictive as well as predictive validity (e.g. see the meta-analysis by Van IJzendoorn, 1995). Test-retest reliability has been established (Bakermans-Kranenburg \& Van IJzendoorn, 1993; Beniot \& Parker, 1994; Sagi et al., 1994b), and in studies conducted in the Netherlands, Israel, and the United States, it has been determined that AAI classifications are not influenced by the participants' verbal and cognitive abilities and memory skills (BakermansKranenburg \& Van IJzendoorn, 1993; Crowell et al., 1993; Sagi et al., 1994b; Waters et al., 1993).

\section{Procedure}

Two trained female interviewers conducted the AAI on site, in kibbutz offices especially selected for the purpose of the study, usually around the same week when the Strange Situation was conducted. Data collection took place between 1988 and 1989 before communal sleeping was eliminated in the kibbutz system. Special attention was made to ensure confidentiality, especially given the data obtained in the Strange Situation and the AAI. It should be noted that an infant's house normally consists of six infants and two caregivers. The number of existing infants' houses in a given kibbutz depends on the annual birth-rate, which changes from year to year and from one kibbutz to another (the average is about $8-15$ infants per year). We approached 50 kibbutz infants' houses through the official channels of the Institute of Research on Kibbutz Education, which monitors all research activities conducted with kibbutz children. One family had to leave the country unexpectedly after we obtained consent but before we visited, and one family withdrew its consent. Because this study is part of a larger project, we were unable to replace these two families. Due to geographical reasons, which prevented us from bringing the infants to the laboratory, the Strange Situation procedure was conducted on-site. Specifically, all observations took place in a room of a children's house other than that in which the infant was housed. Camera operators filmed unobtrusively through a crack in the curtain from outside. A full description of the setting and procedures has been reported in Sagi et al. (1994a). 


\section{RESULTS}

Based on our hypothesis we predicted a significant $3 \times 2 \times 2$ interaction (Mother attachment $\times$ Infant attachment $\times$ Sleeping arrangement). To test this hypothesis, we employed a saturated log-linear model (Feinberg, 1980). Because of small sample size, Es and Ds in the AAI classification were considered as one insecure group for the analyses. The corresponding distributions of Mother Attachment, Infant Attachment, and Sleeping arrangement appear in Table 1.

The log-linear model was confirmed to fit the data $\left[\right.$ Pearson $\chi^{2}(4)=1.57$, $P=.81]$, and the role of the ecological context in the transmission of attachment from parent to child was uncovered. The interaction of Mother Attachment $\times$ Infant Attachment $\times$ Sleeping arrangement was found to be significant $(Z=-1.89, P=.03$, one-tailed). In the home-based sample 19 to 25 dyads $(76 \%)$ mother attachment and infant attachment classifications matched. In the communal setting, only 8 out of $20(40 \%)$ classifications matched. The absence of a significant Mother $\times$ Infant interaction $(z=.52)$, refutes the notion of a transmission hypothesis independent of ecological context. Moreover, the interaction between Sleep $\times$ Mother Attachment was not significant $(z=-.22)$, thus suggesting that mothers from the two ecologies do not differ in distribution of attachment classification $(65 \%$ and $72 \%$ secure in the communal sleeping and home-based arrangements, respectively). Basically, these distributions are consistent with other findings in the field (Van IJzendoorn \& Bakermans-Kranenburg, 1996). Most importantly, the results confirm that the correspondence between Mother Attachment and Infant Attachment depends on the context of the sleeping

\section{TABLE 1}

Correspondence between Infant and Mother Attachment in the Communal and Home-based Kibbutz

\begin{tabular}{|c|c|c|c|c|c|c|c|c|c|}
\hline \multirow[b]{3}{*}{ Infant Attachment ${ }^{\mathrm{a}}$} & \multicolumn{9}{|c|}{ Mother Attachment } \\
\hline & \multicolumn{3}{|c|}{ Total Group } & \multicolumn{3}{|c|}{ Communal } & \multicolumn{3}{|c|}{ Home } \\
\hline & $D$ s & $F$ & $E^{\mathrm{c}}$ & $D$ s & $F$ & $E^{\mathrm{c}}$ & $D$ s & $F$ & $E^{\mathrm{c}}$ \\
\hline Secure & 1 & 22 & 8 & 1 & 6 & 4 & 0 & 16 & 4 \\
\hline Ambivalent ${ }^{\mathrm{b}}$ & 2 & 9 & 3 & 1 & 7 & 1 & 1 & 2 & 2 \\
\hline $\begin{array}{l}\text { Mother-Infant } \\
\text { Correspondence }\end{array}$ & \multicolumn{3}{|c|}{$\frac{27}{45}=60 \%$} & \multicolumn{3}{|c|}{$\frac{8}{20}=40 \%$} & \multicolumn{3}{|c|}{$\frac{19}{25}=76 \%$} \\
\hline
\end{tabular}

${ }^{a}$ No avoidant infant-mother relationships were found in this sample.

${ }^{\mathrm{b}}$ In the communal group, one case was classified as autonomous on the AAI and Insecure-Unclassifiable in the Strange Situation. For analysis purposes, it was considered ambivalent.

${ }^{c}$ In the AAI classification system there is a condition under which both Ds and E characteristics are exhibited to the extent that the transcript becomes insecure-cannotclassify (CC). We have found 2 CC cases which are included in the E group for the purpose of analysis. 
arrangement. Finally, and combining the two settings, we found a higher likelihood for secure than for insecure classifications in parents $(z=-1.64$, $P=.05$, one-tailed) and in the children $(z=-2.05, P=.02$, one-tailed $)$, which is parallel to the overall distribution of normal samples studied thus far (see Van IJzendoorn \& Bakermans-Kranenburg, 1996).

\section{DISCUSSION}

In the present study we took advantage of the unique kibbutz child-rearing system, which has been treated in the literature as furnishing a "natural laboratory" for testing the consequences of child-rearing methods that derived from a unique philosophy and from practices markedly different from those used in the West (Beit-Hallahmi \& Rabin, 1977). More specifically, the quasi-experimental design used in the present study facilitated an examination of intergenerational transmission of attachment with variation in ecological context. Although potential threats for internal validity exist in any quasi-experimental design, we demonstrated the equivalence of the communal and family-based groups with respect to many important and salient variables (Sagi et al., 1994a). It should also be noted that in any quasi-experimental design causal implications cannot be automatically derived from the data (Elliott, 1988; Feinberg, 1980). Because the communal and family-based groups are equivalent with respect to major biographical, parental, and child characteristics as well as to daytime quality of care, we conclude that it is the sleeping arrangement that influenced the association between maternal attachment representations and the child's attachment security.

Our data appear to be compatible with a model of intergenerational transmission of attachment in which the ecological context plays a facilitative or inhibitative role. We have found support for our hypothesis that transmission of attachment across generations is not a universal phenomenon but is dependent on the specific child-rearing arrangement. In kibbutzim with communal sleeping, we did not find a systematic association between maternal attachment representations and her child's attachment security with her. Living in this unique child-rearing ecology mitigated the expected transmission of attachment found in "normal" Western populations as well as in kibbutzim with family-based sleeping arrangements.

Recall that it was hypothesised that in kibbutzim with communal sleeping the transmission of attachment could be impaired in secure mothers, who cannot sensitively interact with their infants; and in turn, this inability to respond sensitively to the infant might be associated with an insecure attachment between the infant and his/her biological mother. More specifically, from the point of view of attachment theory, the continuous 
inaccessibility of the mothers as primary attachment figures at night, without adequate replacement, combined with their being available and responsive during the day, was hypothesised to constitute an inconsistent responsive interaction for the infants (Sagi et al., 1994a). Our data do not confirm this interpretation. The association between the AAI and Strange Situation classifications in the communal sleeping arrangement is found to be random. For example, about the same proportion of secure mothers appear to have infants classified as secure or insecure with them in the Strange Situation. Also, insecure mothers appear to have infants classified as either secure or insecure in the Strange Situation. On the group level therefore, the data seem to indicate that in the communal sleeping arrangement a systematic transmission of attachment across generations is absent, and in fact this nonsystematic process may be due to the restricted sample size, hence precluding any further explanation.

On the individual level, however, one might speculate about specific interpretations. Specifically, we should consider four alternative patterns which appear in our data: (1) secure mothers with secure infants; (2) secure mothers with insecure infants; (3) insecure mothers with insecure infants; (4) insecure mothers with secure infants. Following the literature regarding protective and risk factors in child development (e.g. Sroufe, Cooper, DeHart, \& Marshall, 1992), the first alternative might be explained by the availability of strong protective factors both in children and their parents, which are necessary in order to override the adverse effects of the communal sleeping conditions. With regard to the second alternative, one may easily imagine that such protective factors are absent, and therefore the dyad is more likely to be negatively influenced by the detrimental sleeping context. In the third alternative, risk factors associated with insecure maternal attachment representations, as well as absence of compensatory protective factors in the child, combined with the adverse effects of the communal sleeping arrangement, may result in an insecure infant-parent attachment relationship. The last alternative is, of course, the most difficult to explain. Provided that measurement errors do not account for every instance of the combination of insecure mothers with a secure child, we propose that protective factors in children or in their wider social network might compensate for the negative effects of the sleeping arrangement and that of the insecurity of mothers. It should be pointed out, once again, that the interpretations regarding the foregoing four alternative relationships stem from a dyadic level in the case of sleeping arrangement; the associations between AAI and Strange Situation classifications were nonsignificant, and at the group level of analysis we should therefore view the data as suggesting absence of transmission in kibbutzim with communal sleeping.

Finally, the distributions of secure versus insecure mothers in both kibbutz ecologies were similar (i.e. $65 \%$ secure in communal sleeping; $72 \%$ 
secure in the home-based setting), once again emphasising the equivalence of the two groups in our quasi-experimental design. At the same time the distributions of secure versus insecure infant-mother attachment relationships are very different (i.e. $80 \%$ secure in the home-based setting and $48 \%$ secure in communal sleeping). Therefore, it can be argued that the similarity in the AAI distributions and the dissimilarity in the Strange Situation data together point to a lack of transmission, in particular, in the communal sleeping arrangement. We have to emphasise here that communal sleeping is no longer in effect in Israeli kibbutzim (for review see Aviezer et al., 1994), and therefore this unique group of participants, albeit small, has an important and historical role in studying the interaction between extreme human ecologies and transmission of patterns of attachment. It is therefore impossible to supplement our current data with extensive case studies into the unexpected combination of maternal attachment representations and infant-mother attachments. We propose that attachment researchers merge their data on lack of transmission to facilitate further study of this intriguing phenomenon.

Manuscript received November 1994 Revised manuscript received December 1995

\section{REFERENCES}

Ainsworth, M.D., Blehar, M.C., Waters, E., \& Wall, S. (1978). Patterns of attachment: A psychological study of the Strange Situation. Hillsdale, NJ: Lawrence Erlbaum Associates Inc.

Aviezer, O., Van IJzendoorn, M.H., Sagi, A., \& Schuengel, C. (1994). "Children of the Dream" revisited: 70 years of collective childrearing in Israeli kibbutzim. Psychological Bulletin, 116, 99-116.

Bakermans-Kranenburg,M.J., \& Van IJzendoorn, M.H. (1993). A psychometricstudy of the Adult Attachment Interview: Reliability and discriminant validity. Developmental Psychology, 29, 870-880.

Beit-Hallahmi, B., \& Rabin, A. (1977). The kibbutz as a social experiment and as a child-rearing laboratory. American Psychologist, 12, 57-69.

Benoit, D., \& Parker, K.C.H. (1994). Stability and transmission of attachment across three generations. Child Development, 65, 1444-1456.

Bowlby, J. (1973). Attachment and loss: Vol. 2. Separation. New York: Basic Books.

Bowlby, J. (1984). Attachment and loss: Vol. 1. Attachment (2nd ed.). London: Pelican.

Crowell, J., Waters, E., Treboux, D., Posada, G., O’Connor, E., Colon-Downs, C., Feiden, O., Fleischman, M., Gao, Y., Golby, B., Lay, K-L., \& Pan, H. (1993, March). Validity of the Adult Attachment Interview: Does it measure what it should? Paper presented at the 60th Meeting of the Society for Research in Child Development, New Orleans, Louisiana.

Elliott, G.C. (1988). Interpreting higher order interactions in log-linear analysis. Psychological Bulletin, 103, 121-130.

Feinberg, S.E. (1980). The analysis of cross-classified categorical data (2nd ed.). Cambridge, MA: MIT. 
Feldman, S.S., \& Yirmiya, N. (1986). Perception of socialization roles: A study of Israeli mothers in town and kibbutz. International Journal of Psychology, 21, 153-165.

George, C., Kaplan, N., \& Main, M. (1985). Adult Attachment Interview. Unpublished manuscript, University of California, Berkeley, CA.

Lamb, M.E., Thompson, R.A., Gardner, W., \& Charnov, E.L. (1985). Infant-mother attachment: The origins and developmental significance of individual differences in Strange Situation behavior. Hillsdale, NJ: Lawrence Erlbaum Associates Inc.

Lavi, Z. (1990). Introduction. In Z. Lavi (Ed.), Kibbutz members study kibbutz children (pp. 1-16). New York: Greenwood.

Main, M., \& Goldwyn, R. (1994). Adult Attachment Classification System. Unpublished manuscript. University of California, Berkeley, CA.

Main, M., Kaplan, N., \& Cassidy, J. (1985). Security in infancy, childhood and adulthood: A move to the level of representation. In I. Bretherton \& E. Waters (Eds.), Growing points in attachment: Theory and research. Monographs of the Society for Research in Child Development, 50 (1-2, Serial No. 209), 66-104. Chicago: University of Chicago Press.

Main, M., \& Solomon, J. (1990). Procedures for identifying infants as disorganized/ disoriented during the Ainsworth Strange Situation. In M.T. Greenberg, D. Cicchetti, \& E.M. Cummings (Eds.), Attachment in preschool years: Theory, research, and intervention (pp. 121-160). Chicago: University of Chicago Press.

Oppenheim,D., Sagi, A., \& Lamb, M.E. (1988). Infant-adult attachments on the kibbutz and their relation to socioemotional development four years later. Developmental Psychology, 24, 427-433.

Rabin, A.I., \& Beit-Hallahmi, B. (1982). Twenty years later. New York: Springer.

Rutter, M., Quinton, D., \& Hill, J. (1990). Adult outcome of institution-reared children: Males and females compared. In L. Robins \& M. Rutter (Eds.), Straight and devious pathways from childhood to adulthood (pp.135-157). Cambridge, UK: Cambridge University Press.

Sagi, A., Koren, N., \& Weinberg, M. (1987). Fathers in Israel. In M.E. Lamb (Ed.), The father's role: Cross-cultural perspectives (pp. 197-226). Hillsdale, NJ: Lawrence Erlbaum Associates Inc.

Sagi, A., Lamb, M.E. Lewkowicz, K., Shoham, R., Dvir, R., \& Estes, D. (1985). Security of infant-mother, -father, and -metapelet attachments among kibbutz-reared Israeli children. Monographs of the Society for Research in Child Development, 50, 257-275 (1-2, Serial No. 209). Chicago: University of Chicago Press.

Sagi, A., Resnick, G., Aviezer, O., Gini, M., Bar-Haim, Y., \& Berson, Y. (1995, March). A ten-year follow-up of attachment: The case of personal space. Poster presented at the 61st Meeting of the Society for Research in Child Development, Indianapolis, IA.

Sagi, A., Van IJzendoorn, M.H., Aviezer, O., Donnell,F., \& Mayseless, O. (1994a). Sleeping out of home in a kibbutz communal arrangement: It makes a difference for infant-mother attachment. Child Development, 65, 992-1004.

Sagi, A., Van IJzendoorn, M.H., Scharf, M., Koren-Karie, N., Joels, T., \& Mayseless, O. (1994b). Stability and discriminant validity of the Adult Attachment Interview: A psychometric study in young Israeli adults. Developmental Psychology, 30, 771-777.

Sroufe, L.A. (1988). The role of infant-caregiver attachment in development. In J. Belsky \& T. Nezworski (Eds.), Clinical implications of attachment (pp. 18-40). Hillsdale, NJ: Lawrence Erlbaum Associates Inc.

Sroufe, L.A., Cooper, R.G., DeHart, G.B., \& Marshall, M.E. (1992). Child development. Its nature and course (2nd ed.). New York: McGraw-Hill.

Van IJzendoorn, M.H. (1992). Intergenerational transmission of parenting: A review of studies in nonclinical populations. Developmental Review, 12, 76-99. 
Van IJzendoorn, M.H. (1995). Associations between Adult Attachment representations and parent-child attachment, parental responsiveness, and clinical status: A meta-analysis on the predictive validity of the Adult Attachment Interview. Psychological Bulletin, 117, 387-403.

Van IJzendoorn, M.H., \& Bakermans-Kranenburg, M.J. (1996). Attachment representations in mothers, fathers, adolescents, and clinical groups: A meta-analyticsearch for normative data. Journal of Consulting and Clinical Psychology, 64, 8-21.

Van IJzendoorn, M.H., Sagi, A., \& Lambermon, M.W.E. (1992). The multiple caretaker paradox: Some data from Holland and Israel. In R.C. Pianta (Ed.), Relationships between children and non-parental adults [special issue]. New Dirctions in Child Development, 57, 5-24.

Waters, E., Crowell, J., Treboux, D., O’Connor, E., Posada, G., \& Golby, B. (1993, March). Discriminant validity of the Adult Attachment Interview. Poster presented at the 60th Meeting of the Society for Research in Child Development, New Orleans, LA. 